\title{
Awareness of the Red Dress Symbol and Heart Disease Among College Women
}

\author{
Sandra L. Anderson, Kathryn Silliman, Julie M. Schneider \\ California State University, Chico
}

\begin{abstract}
The purpose of this study was to determine the level of concern and knowledge about heart disease among college women and to explore the relationship between awareness of the Red Dress symbol and knowledge of risk factors for heart disease. Female college students $(n=475)$ completed a survey. While $63 \%$ believed they are informed about heart disease, only $43 \%$ identified heart disease as the leading cause of death in women. Breast cancer $(36 \%)$ was listed as the one greatest health concern facing women, followed by heart disease (29\%). Chi-square analysis revealed that a significantly greater proportion of participants familiar with the Red Dress symbol $(n=157)$ identified heart disease as the greatest health problem facing women and the leading cause of death of women than participants unfamiliar with the symbol $(\mathrm{n}=318)$. Participants familiar with the symbol identified 0.4-0.5 more correct choices on two questions related to causes of and activities to prevent heart disease than women unfamiliar with the symbol. College women are a prime target for a Red Dress campaign due to their low level of awareness. Young women can reduce their risk of developing heart disease through prevention.
\end{abstract}

(C) 2013 Californian Journal of Health Promotion. All rights reserved.

Keywords: heart disease, college students, health knowledge, women's health, health campaigns

\section{Introduction}

Cardiovascular disease or heart disease is the leading cause of death in the United States. On average, one American dies every 39 seconds from cardiovascular disease (Roger et al., 2012). More women die each year of cardiovascular disease than men (Women Heart, 2012). In 2008, 419,730 women died from cardiovascular disease, representing more deaths than from cancer, chronic lower respiratory disease and Alzheimer's disease combined (Roger et al., 2012). Because of the low level of women's awareness of heart disease, in 2002 the National Heart, Lung, and Blood Institute created the Heart Truth Campaign (National Heart, Lung and Blood Institute, 2012) and in 2004 the American Heart Association (AHA) launched Go Red for Women (American Heart Association, 2012). The symbol for both these campaigns is the Red Dress. The AHA hopes these campaigns will help all women improve their heart health through heart disease awareness and preventative actions.

\section{The Red Dress Symbol}

The Red Dress symbol and the Heart Truth Campaign have the potential to impact women's awareness and knowledge of heart disease and improve women's health behaviors like the pink ribbon symbol has accomplished for breast cancer. The pink ribbon is one of the most recognized symbols in the United States and is most likely one of the reasons for the dramatic increase in the number women who receive annual mammograms (Harvey \& Strahilevitz, 2009). Study participants who are exposed to heart health campaigns or interventions show greater or improved knowledge of heart disease (Jones, Weaver \& Friedman, 2007; Koffman et al., 2001; Pazoki, Nabipour, Seyednezami \& Imami, 2007; Villablanca et al., 2009). Heart health educational interventions also lead to behavior changes among study participants such 
as increased activity level (Koffman et al., 2001; Pazoki et al., 2007), improved diet (Koffman et al., 2001) and changes in biomarkers such as reduced systolic blood pressure (Pazoki et al., 2007; Villablanca et al., 2009).

The American Heart Association (AHA) has tracked women's awareness of heart disease since 1997 , when less than $33 \%$ of U.S. women identified heart disease as the leading cause of death among women and only $8 \%$ identified heart disease as the greatest health problem facing women (Mosca et al., 2000). The most recent AHA survey found women's awareness of heart disease as the leading cause of death increased to $54 \%$ and identification of heart disease as the greatest health problem facing women increased to $16 \%$ (Mosca, MochariGreenberger, Dolor, Newby \& Robb, 2010). This increase in awareness may be related to the introduction of the Red Dress campaign and symbol in 2004. The 2005 and 2009 AHA surveys found that $68-69 \%$ of women who had seen, heard, or read anything about the Red Dress symbol knew heart disease was the leading cause of death of women compared to only $43-51 \%$ of those who were not familiar with the symbol (Mosca et al., 2006; Mosca et al., 2010). Proportionately (near 90\%) more women in North Dakota understood that heart disease was the leading cause of death among women where nearly all study participants were exposed to the Red Dress symbol as part of the Go Red North Dakota program (Mozumdar \& Liguori, 2010).

\section{Demographic Differences in Awareness of Women's Heart Disease Risk}

Demographic factors, such as ethnicity and age, are associated with awareness of heart disease. In national studies, African American and Hispanic women were less aware of heart disease as the leading cause of death of women than white women (Christian, Rosamond, White \& Mosca, 2007; Mochari-Greenberger, Mills, Simpson \& Mosca 2010; Mosca et al., 2010). This is of concern because these ethnic groups have greater prevalence of risk factors associated with heart disease (Roger et al., 2012). At least one AHA survey among women 25 years of age and older reported that younger women were less aware of women's heart disease risk than older women (Mosca, Ferris, Fabunmi \& Robertson, 2004). At the time of this study, there was limited research on the awareness of heart disease among women younger than 25 years and among college students. A 2004 survey (Collins, Dantico, Shearer \& Mossman, 2004) of male and female college students in Arizona found that only $25 \%$ recognized heart disease as the most common cause of death among women. A more recent 2010 cross-sectional survey (Munoz et al., 2010) completed by female college students in Texas indicated that $55 \%$ recognized cardiovascular disease as the leading cause of death among women.

\section{The Present Study}

Education and prevention of the number one killer among women should be paramount. Because heart disease is a chronic disease that progresses over time, targeting women at a young age would enable them to make lifestyle changes to slow its progression or prevent it. Optimally, the Red Dress symbol for heart disease should be as easily recognized as the pink ribbon is for breast cancer. Since there is limited research on heart disease awareness among college women, the purpose of this study was to determine the level of concern and knowledge about heart disease and to explore the relationship between awareness of the Red Dress symbol and knowledge of risk factors for heart disease.

\section{Methods}

\section{Participants and Procedures}

The institutional review board at California State University (CSU), Chico approved this crosssectional study. CSU, Chico is located in a rural community 90 miles north of Sacramento. Its service area includes 12 counties in northern California. Instructors of students enrolled in upper and lower division general education courses at the university were contacted and permission was obtained to enter their classes and use class time to administer surveys during the spring semester of 2008. Consent was obtained from students prior to administering the paper survey. Over $95 \%$ of students approached 
agreed to complete the survey. Both male and female students 18 years of age or older completed the surveys but only the surveys from female students were analyzed $(n=475)$.

\section{Survey Instrument}

The survey used in the current study was modified (shortened version) from the 2006 American Heart Association's Women's Health Tracking survey (K. Robb, personal communication, November 20, 2007). The survey had 14 items. There were five demographic questions and two questions regarding knowledge of health issues in general (greatest health problem facing women and leading cause of death for women). To determine the level of concern about heart disease, the survey asked participants to rate how worried they were about getting a list of nine diseases, including heart disease, on a 3 point Likert scale from 1 ("worry a lot") to 3 ("do not worry"), with an option for "don't know." One question asked how well informed they were about heart disease on a 4 point Likert scale from 1 ("very well informed") to 4 ("not at all informed") with an option for "don't know." There were two questions regarding familiarity of the Red Dress symbol (have they seen it and do they know what organization uses it). Two questions assessed knowledge of major causes of heart disease and lifestyle activities which may prevent heart disease, from a list of 16 choices with an option for "don't know," 9 of the 16 items listed were correct based on the American Heart Association's identified major risk factors and life style changes (American Heart Association, 2012). One final question determined the participants' sources of information about heart disease.

\section{Statistical Analyses}

IBM SPSS version 19.0 for Windows (2010, IBM Inc, Armonk, New York) was used to analyze the data. Descriptive statistics provided means, standard deviations, percentages, and frequencies for the variables of interest. Chisquare analyses were used to determine differences in demographics between participants familiar and unfamiliar with the Red of 9 correct choices) on the two questions about major risk factors for heart disease and activities to prevent heart disease among the subgroups described. Answers to the following questions were dichotomized into subgroups: class rank as a proxy for age (lower and upper class); ethnicity (Caucasian and other races); parental education level (some college or less and college degrees or more); those familiar versus unfamiliar with Red Dress symbol; those informed (moderately to very well informed) versus not informed (not informed or don't know) of heart disease; those correctly identifying heart disease as the greatest problem facing women versus those who did not identify it; and those correctly identifying heart disease as leading cause of death versus those who did not identify it. Where $T$-tests found significant differences in the mean number of correctly identified choices by the subgroups described above, interactions between these subgroups were examined using two-way ANOVAs.

\section{Results}

\section{Participants' Demographic Characteristics}

The ages of the women who completed the survey ranged from 18 to 51 years with a mean of 20 years $(\mathrm{SD}=3)$ which was slightly younger than the mean age for CSU, Chico students $(\mathrm{M}=$ 22). The demographic characteristics of the women who completed the survey compared to the demographic profile of CSU, Chico are presented in Table 1. The majority of participants were freshmen and sophomores, and were Caucasian. The majority of parents of survey participants had some college education or post-graduate degrees.

\section{Participants' Knowledge about Heart Disease} When asked about the leading cause of death for all women, $43 \%(n=203)$ correctly identified heart disease followed by general cancer $(16 \%$, $n=76)$ ) and breast cancer $(16 \%, n=74)$. Participant were asked "what do you think is the one greatest health problem facing women today?" and $36 \%(\mathrm{n}=172)$ selected breast cancer while only $29 \%(\mathrm{n}=136)$ selected heart disease and $15 \%(\mathrm{n}=73)$ selected general cancer. Similarly, when asked how worried they were about getting a list of diseases, 27\% ( $n=$ 127) worry about breast cancer, followed by general cancer $(26 \%, n=122)$ and obesity $(18 \%$, 
Table 1

\begin{tabular}{|c|c|c|c|}
\hline \multirow{3}{*}{$\begin{array}{l}\text { Demographic } P \\
\text { Compared to C } \\
\text { 2007) }\end{array}$} & \multicolumn{3}{|c|}{$\begin{array}{l}\text { Profile of Participants } \\
\text { CSU, Chico Profile (Fall }\end{array}$} \\
\hline & \multicolumn{2}{|c|}{$\begin{array}{l}\text { Study } \\
\text { Participants } \\
(\mathrm{n}=475)\end{array}$} & \multirow{2}{*}{$\begin{array}{l}\text { CSU } \\
\text { Chico } \\
(N= \\
17,034) \\
\%\end{array}$} \\
\hline & $\mathrm{n}$ & $\%$ & \\
\hline \multicolumn{4}{|l|}{ Class Rank } \\
\hline Freshmen & 140 & 30 & 25 \\
\hline Sophomore & 146 & 31 & 15 \\
\hline Junior & 126 & 26 & 22 \\
\hline Senior & 13 & 13 & 30 \\
\hline \multicolumn{4}{|l|}{ Ethnicity } \\
\hline African American & 13 & 2.7 & 1.9 \\
\hline American Indian & 5 & 1.1 & 1.1 \\
\hline Asian & 31 & 6.5 & 6.9 \\
\hline Caucasian & 352 & 74.1 & 65.4 \\
\hline Hispanic & 52 & 10.9 & 12.3 \\
\hline Other & 22 & 4.6 & 12.3 \\
\hline $\begin{array}{l}\text { Parent Education } \\
\text { Level }\end{array}$ & & & \\
\hline $\begin{array}{l}\text { Less than high } \\
\text { school }\end{array}$ & 29 & 6.1 & $*$ \\
\hline High school & 43 & 9.1 & $*$ \\
\hline Some college & 184 & 38.7 & $*$ \\
\hline College graduate & 137 & 28.8 & $*$ \\
\hline Post graduate & 82 & 17.3 & $*$ \\
\hline
\end{tabular}

*Information not available

$n=86)$, while only $17.7 \%(n=82)$ were worried about getting heart disease. To determine participants' perceived knowledge, participants were asked how informed they were about heart disease in women, the majority $(63 \%, n=297)$ felt they were moderately to very well informed. The participants indicated that their top sources of information about heart disease come from television $(56 \%, n=265)$, magazines or newspapers $(50 \%, n=235)$, and/or a college course $(44 \%, n=207)$. The top correctly identified major risk factors for heart disease were being overweight $(83 \%, n=396)$, family history $(83 \%, n=395)$ and high blood pressure $(80 \%, n=380)$, and the top correctly identified preventative activities for heart disease were physical exercise (92\%, $n=439)$, losing weight $(78 \%, n=371)$ and healthy blood pressure $(77 \%, n=367)$.

Thirty-three percent $(n=157)$ of the women responded that "they had seen, heard or read about the Red Dress symbol." Of these participants, only one of them identified National Heart, Lung and Blood Institute and 117 identified American Heart Association as organizations using the Red Dress symbol.

\section{Demographic Differences in Awareness of the Red Dress Symbol}

Survey responses were compared among women who were and were not familiar with the Red Dress symbol (Table 2). A larger proportion of participants who were familiar with the Red Dress symbol were Caucasian, older (juniors and seniors), identified heart disease as the greatest health problem facing women and the leading cause of death for women, and perceived themselves to be moderately to very well informed about heart disease than participants unfamiliar with the symbol.

\section{Subgroup Differences in Awareness of Heart Disease Risk Factors}

There was no difference in the mean number of correctly identified choices (out of 9 correct choices) to the two heart disease knowledge questions by class rank (as a proxy for age) or parental educational level ( $T$-tests, data not shown). However, as shown in Table 3 , the mean number of correct choices to questions about major causes of heart disease and activities to prevent heart disease were significantly higher in: 1) the group of women who perceived themselves to be moderately to very well informed about heart disease compared to the group not informed, 2) the group of women who identified heart disease as the greatest problem facing women compared to the group who failed to identify it, and 3) the group of women who identified the leading cause of death among women as heart disease compared to the group that failed to identify it. Women who stated they were familiar with the Red Dress symbol identified almost significantly 
Table 2

Responses to Survey Questions Among Those Familiar and Unfamiliar With The Red Dress Symbol

\begin{tabular}{|c|c|c|c|c|c|c|}
\hline & \multicolumn{2}{|c|}{$\begin{array}{l}\text { Familiar } \\
(n=157)\end{array}$} & \multicolumn{2}{|c|}{$\begin{array}{l}\text { Unfamiliar } \\
(n=318)\end{array}$} & \multirow[b]{2}{*}{$X^{2}$} & \multirow[b]{2}{*}{$p$} \\
\hline & $\mathrm{n}$ & $\%$ & $\mathrm{n}$ & $\%$ & & \\
\hline Ethnicity & & & & & 7.9 & .005 \\
\hline Caucasian & 129 & 82.2 & 223 & 70.1 & & \\
\hline All other & 28 & 17.8 & 95 & 29.9 & & \\
\hline Class Rank & & & & & 20.2 & .001 \\
\hline Freshman and sophomore & 72 & 45.9 & 214 & 67.3 & & \\
\hline Junior and senior & 85 & 54.1 & 104 & 32.7 & & \\
\hline Parents Education & & & & & 1.1 & .292 \\
\hline Less than high school to some college & 90 & 57.3 & 166 & 52.2 & & \\
\hline College to post graduate & 67 & 42.7 & 152 & 47.8 & & \\
\hline Greatest Health Problem Facing Women & & & & & 26.1 & .001 \\
\hline Heart disease & 68 & 43.3 & 68 & 21.4 & & \\
\hline Breast cancer & 40 & 25.5 & 132 & 41.5 & & \\
\hline Cancer (general) and all others & 49 & 31.2 & 118 & 37.1 & & \\
\hline Leading Cause of Death for Women & & & & & 42.6 & .001 \\
\hline Heart disease & 100 & 63.7 & 103 & 32.4 & & \\
\hline Breast cancer & 18 & 11.5 & 56 & 17.6 & & \\
\hline Cancer (general) and all others & 39 & 24.8 & 159 & 50.0 & & \\
\hline Informed About Heart Disease & & & & & 31.5 & .001 \\
\hline Not at all informed or don't know & 31 & 19.7 & 147 & 46.2 & & \\
\hline Moderately informed to very well informed & 126 & 80.2 & 171 & 53.8 & & \\
\hline
\end{tabular}

more correct choices on the question related to preventative activities and more correct choices on the question related to major causes than women unfamiliar with the symbol. Thus, there appeared to be an association between awareness of heart disease or the Red Dress symbol and knowledge of risk factors for heart disease. Caucasians identified significantly more correct choices on both knowledge questions than other ethnic groups.

Two-way ANOVA allowed us to explore the independent and joint effects of: (1) ethnicity and awareness of women's risk for heart disease on the mean number of correctly identified major causes or preventative activities, and (2) ethnicity and awareness the Red Dress symbol on the mean number of correctly identified major causes or preventative activities. The results were similar to Table 3 . The main effects for ethnicity and awareness of heart disease or ethnicity and familiarity with the Red Dress symbol were significant but the interactions were not. Thus, awareness of heart disease or the Red Dress symbol and ethnicity appear to be independently associated with knowledge of heart disease risk factors and preventative activities.

\section{Discussion}

The results of this cross-sectional survey of female students at a rural public university, where Caucasians were the majority, demonstrate that although most of women surveyed $(63 \%)$ believe they were moderately to very well informed about heart disease, heart disease awareness was low. Only $43 \%$ correctly identified heart disease as the leading cause of death among women. Another recent study found $55 \%$ of college women are aware that heart disease is the number one killer of women (Munoz et al., 2010). 
Table 3

Perceived Knowledge of Heart Disease, Familiarity With Red Dress Symbol, and Ethnicity By Number of Correct Choices to Heart Disease Questions

\begin{tabular}{|c|c|c|c|c|c|c|c|}
\hline & \multirow{2}{*}{\multicolumn{4}{|c|}{$\begin{array}{l}\text { Number of Correct Choice } \\
\text { Maior Causes } 1\end{array}$}} & \multirow{2}{*}{\multicolumn{3}{|c|}{ Preventative Activities ${ }^{2}$}} \\
\hline & & & & & & & \\
\hline & $\mathrm{n}$ & $\mathrm{M} \pm \mathrm{SD}$ & $t$ & $p$ & $\mathrm{M} \pm \mathrm{SD}$ & $\mathrm{t}$ & $p$ \\
\hline Perceived awareness of heart disease & & & 4.0 & $<.001$ & & 3.6 & $<.001$ \\
\hline Moderately to very well informed & 297 & $5.5 \pm 1.9$ & & & $6.7 \pm 2.1$ & & \\
\hline Don't know or not informed & 178 & $4.7 \pm 2.3$ & & & $5.8 \pm 2.7$ & & \\
\hline Greatest health problem women face & & & 4.1 & $<.001$ & & 3.3 & .001 \\
\hline Heart disease & 136 & $5.8 \pm 1.8$ & & & $6.9 \pm 2.0$ & & \\
\hline Other diseases or don't know & 339 & $5.0 \pm 2.2$ & & & $6.1 \pm 2.5$ & & \\
\hline Leading cause of death for women & & & 5.1 & $<.001$ & & 4.0 & $<.001$ \\
\hline Heart disease & 203 & $5.7 \pm 1.8$ & & & $6.8 \pm 2.1$ & & \\
\hline Other diseases or don't know & 272 & $4.8 \pm 2.2$ & & & $6.0 \pm 2.6$ & & \\
\hline Familiar with Red Dress symbol & & & -1.9 & .059 & & -2.3 & .021 \\
\hline Yes & 157 & $5.5 \pm 1.9$ & & & $6.7 \pm 2.2$ & & \\
\hline No & 318 & $5.1 \pm 2.2$ & & & $6.2 \pm 2.5$ & & \\
\hline Ethnicity & & & 4.0 & .001 & & 3.6 & .001 \\
\hline Caucasian & 297 & $5.5 \pm 1.9$ & & & $6.7 \pm 2.1$ & & \\
\hline All other & 178 & $4.7 \pm 2.3$ & & & $5.8 \pm 2.7$ & & \\
\hline
\end{tabular}

${ }^{1}$ Number of correctly identified major causes of heart disease in women out of 9 .

${ }^{2}$ Number of correctly identified activities that may prevent heart disease out of 9 .

Despite the majority of participants being unaware that heart disease is the number one cause of death among women, most appear to be familiar with some of the risk factors for heart disease or ways to prevent it. Consistent with other studies (Collins et al., 2004; Mosca et al., 2004), participants identified risk factors for heart disease including being overweight, family history of heart disease and high blood pressure. The activities to prevent or reduce risk of heart disease identified by participants included physical exercise, healthy blood pressure and losing weight. These are the same activities recognized by female subjects in other studies (Mosca et al., 2004; Munoz et al., 2010). Lesser known risk factors such as elevated blood cholesterol, diabetes, and smoking can be used in a heart disease campaign targeted at younger women. To inform this population about these risk factors, the media may be a useful tool. The main sources of information about heart disease reported by participants in the current study were television, magazines or newspapers. Likewise, other studies report top sources of information about heart disease were television and magazines (Mosca et al., 2010; Munoz et al., 2010), or the Internet (Munoz et al., 2010).

When we asked what the greatest health problem facing women, more participants selected breast cancer than heart disease. These findings are quite similar to Munoz et al. (2010) and the AHA survey (Mosca et al., 2010). Similarly, when we asked our participants to choose from a list of diseases, more were worried about getting breast cancer, cancer, or obesity than heart disease. This high level of concern about cancer among younger individuals is also reflected in a previous survey (Collins et al., 2004) and may be the result of breast cancer awareness campaigns on college campuses. California State University, Chico has provided information to raise awareness of breast cancer since at least 2003 (Student Health Center, California State University, Chico, 2004).

In the current survey, only a third of participants responded that they were familiar with the Red 
Dress symbol. This low level of familiarity with the Red Dress symbol among women was also reported in a previous survey (Mosca et al., 2006). We found an association between familiarity with the Red Dress symbol and heart disease knowledge. Of those participants who were familiar with the Red Dress symbol, 64\% correctly identified heart disease as the leading cause of death for women compared to only $32 \%$ unfamiliar with the symbol, and $43 \%$ felt that heart disease was the greatest problem facing women today compared to only $21 \%$ unfamiliar with the symbol. We also analyzed two questions asking participants to identify major causes of heart disease and activities to prevent heart disease. We found that participants familiar with the Red Dress symbol and whose survey responses indicated greater awareness of heart disease correctly identified more risk factors and preventative activities than those unfamiliar with the symbol. We also found that ethnicity was independently associated with knowledge of heart disease. Raising awareness of heart disease among young women may improve their knowledge of risk factors and is the first step towards prevention. Heart health campaigns should be as common on college campuses as breast cancer awareness efforts. These campaigns should target minority groups who are known to have lower levels of awareness but also greater prevalence of risk factors associated with heart disease (Roger et al., 2012).

\section{Limitations}

The results from this study, which used a non- randomized sample of predominately Caucasian female students from a rural public university in northern California, cannot be generalized to female college students in the United States. The survey used in the current study was a shortened version of the 2006 American Heart Association's Women's Health Tracking survey and administered differently (administered in person and not by telephone). While we found associations between familiarity of the Red Dress symbol and knowledge in this crosssectional study, we do not know if being familiar with the Red Dress symbol causes increased knowledge or leads to changes in lifestyle behaviors to prevent heart disease. Thus, findings should be interpreted with caution.

\section{Conclusion}

Our study found that there is a low level of awareness of heart disease among college women. Only a minority were familiar with the Red Dress symbol. This study has shown that women with knowledge of the Red Dress symbol/campaign are significantly more aware of heart disease as the leading cause of death among women and can identify more causes of heart disease and activities preventing heart disease than their counterparts. College and university campuses are an ideal place to educate young women about cardiovascular disease. Red Dress educational activities should be promoted by campus' student health centers and wellness programs. Even young women can make lifestyle changes to improve their heart health and prevent future heart disease.

\section{References}

American Heart Association. (2012). Go Red for Women. About the movement. Retrieved from http://www.goredforwomen.org/about_the_movement.aspx. Accessed January 31, 2012.

American Heart Association. (2012). Heart attack. Retrieved from http://www.heart.org/HEARTORG/Conditions/HeartAttack/HeartAttack_UCM_001092_SubHomePage.jsp. Accessed January 31, 2012.

Christian, A.H., Rosamond, W., White, A.R., \& Mosca, L. (2007). Nine-year trends and racial and ethnic disparities in women's awareness of heart disease and stroke: an American Heart Association national study. Journal of Women's Health, 16 (1), 68-81. doi: 10.1089/jwh.2006.M072

Collins, K.M., Dantico, M., Shearer, N.B.C., \& Mossman, K.L. (2004). Heart disease awareness among college students. Journal of Community Health, 29 (5), 405-420.

Harvey, J.A. \& Strahilevitz, M.A. (2009). The power of pink: Cause-related marketing and 
the impact on breast cancer. Journal of the American College of Radiology 6, 26-32. doi: 10.1016/.jacr.2008.07.010

Jones, D.E., Weaver, M.T., \& Friedmann, E. (2007). Promoting heart health in women. A workplace intervention to improve knowledge and perceptions of susceptibility to heart disease. American Association of Occupational Health Nurses Journal, 55 (7), 271-276.

Koffman, D., Bassarre, T., Mosca, L., Redberg, R., Schmid, T., \& Wasttigney, W. (2001). An evaluation of Choose to Move 1999: an American Heart Association physical activity program for women. Archives of Internal Medicine, 161 (18), 2193-2199.

Mochari-Greenberger, H., Mills, T., Simpson, S.L., \& Mosca, L. (2010). Knowledge, preventive action, and barriers to cardiovascular disease prevention by race and ethnicity in women: An American Heart Association national survey. Journal of Women's Health, 19 (7), 1243-1249. Doi: 10.1089=jwh.2009.1749

Mosca, L., Jones, W.K., King, K.B, Ouyang, P., Redberg, R.F., \& Hill, M.N. (2000). Awareness, perception, and knowledge of heart disease risk and prevention among women in the United States. Archives of Family Medicine, 9, 506-515.

Mosca, L., Ferris, A., Fabunmi, R., \& Robertson, R (2004). Tracking women's awareness of heart disease. An American Heart Association national study. Circulation, 109, 573-579. doi: 10.1161/01.CIR.0000115222.69428.C9

Mosca, L., Mochari, H., Christian, A., Berra, K., Taubert, K., Mills, T., ...Simpson, S.L. (2006). National study of women's awareness, preventive action, and barriers to cardiovascular health. Circulation, 113, 525-534. doi: 10.1161/CIRCULATIONAHA.105.588103

Mosca, L., Mochari-Greenberger, H., Dolor, R.J., Newby, L.K., \& Robb, K.J. (2010). Twelve-year follow-up of American women's awareness of cardiovascular disease risk and barriers to heart health. Circulation: Cardiovascular Quality and Outcomes, 3, 120-127. doi: 10.1161/CIRCOUTCOMES.109.915538

Mozumdar, A., \& Gary Liguori, G. (2010). Statewide awareness study on personal risks of cardiovascular disease in women: a Go Red North Dakota study. Women's Health, 6 (1), 37-50.

Munoz, L.R., Etnyre, A., Adams, M., Herbers, S., Witte, A., Horlen, C., ...Jones, M.E. (2010). Awareness of heart disease among female college students. Journal of Women's Health, 19 (12), 2253-2259. doi: 10.1089=jwh.2009.1635

National Heart, Lung, and Blood Institute. (2012). National Institute of Health. The Hearth Truth. Retrieved from: http://www.nhlbi.nih.gov/educational/hearttruth/about/index.htm. Accessed January 31, 2012.

Pazoki, R., Nabipour, I., Seyednezami, N., \& Imami, S.R. (2007). Effects of a community-based healthy heart program on increasing healthy women's physical activity: a randomized controlled trial guided by Community-based Participatory Research (CBPR). BMC Public Health 7, 216. doi:10.1186/1471-2458-7-216

Roger, V.L, Go, A.S., Lloyd-Jones, D.M., Benjamin, E.J., Berry, J.D., Borden, W.B., ... Turner, M.B. (2012). Heart disease and stroke statistics--2012 update: A report from the American Heart Association. Circulation, 125, e12-e230. doi: 10.1161/CIR.0b013e31823ac046

Student Health Service. California State University, Chico. (2004). Retrieved from http://www.csuchico.edu/vpaa/wasc/docs/CPR_Standard_4/CFR_4.6/SA/SHSGoals03-04.pdf. Accessed August 19, 2012.

Villablanca, A.C., Arline, A., Lewis, J., Raju, S., Sanders, S., \& Carrow, S (2009). Outcomes of national community organization cardiovascular prevention programs for high-risk women. Journal of Cardiovascular Translational Research, 2 (3), 306-320. doi: 10.1007/s12265-009-9118-5

Women Heart. (2012). Women \& Heart Disease Fact Sheet. Retrieved from http://www.womenheart.org/resources/upload/Women-and-Heart-Disease-FINAL-2011.pdf. Accessed January 31, 2012. 


\author{
Author Information \\ *Kathryn Silliman, PhD, RD \\ Department of Nutrition and Food Sciences \\ California State University, Chico \\ Chico, California 95929-0002 \\ Telephone: 530-898-6245 \\ Fax: 530-898-5586 \\ E-mail: ksilliman@csuchico.edu \\ Sandra Anderson, MS, RD \\ Department of Nutrition and Food Sciences \\ California State University, Chico \\ Julie Schneider, $\mathrm{PhD}$ \\ Department of Nutrition and Food Sciences \\ California State University, Chico \\ *corresponding author
}

